\title{
Phubbing and What Could Be Its Determinants: A Dugout of Literature
}

\author{
Thseen Nazir, Sefa Bulut \\ Counseling and Guidance Department, Ibn Haldun University, Istanbul, Turkey \\ Email: thseen.nazir@ihu.edu.tr, sefabulut22@gmail.com
}

How to cite this paper: Nazir, T., \& Bulut, S. (2019). Phubbing and What Could Be Its Determinants: A Dugout of Literature Psychology, 10, 819-829.

https://doi.org/10.4236/psych.2019.106053

Received: March 27, 2019

Accepted: May 12, 2019

Published: May 15, 2019

Copyright $\odot 2019$ by author(s) and Scientific Research Publishing Inc. This work is licensed under the Creative Commons Attribution International License (CC BY 4.0).

http://creativecommons.org/licenses/by/4.0/

\begin{abstract}
Smartphone technology turned life easy but it also complicated many things in human lives. One of the biggest issues nowadays, which rose by smartphones, is its overuse and it had been studied under the banner of addiction. A different kind of issue arose similar to smartphone addiction when people overuse their smartphones in social settings. This phenomenon has been termed as "Phubbing" when a person uses his smartphone and literally ignores the person beside him. This phenomenon is very new and researchers are trying hard to understand the phenomenon so they can predict the determinants of this phenomenon. The aim of this article is to understand the previous researches, which had been done in the area of smartphone addiction and try to understand the similarities and differences in both the phenomenon. This article tries to dig out the available literature to find out what actually Phubbing is and what can be its true determinants. In addition, it tried to understand various types of addictions, which can elevate the Phubbing behavior in different settings. In the light of definition and current understanding of Phubbing, it will try to understand how various types of addictions will help us to understand it in depth. This study analyzes previous researches done on addiction and researches related to Phubbing, and tries to understand the correlation of various addictive behaviors with Phubbing phenomenon.
\end{abstract}

\section{Keywords}

Phubbing, Smartphones, Addiction, Determinants

\section{Introduction}

Smartphone technology had invaded our social life as well as our personal life. According to the online statistics research by Statista, the number of smartphone 
users in the world is expected to pass five billion by 2019. No doubt, smartphone technology had bought huge changes in our lives, which made our lives easy, and on the other hand, it had drawbacks, which are becoming a huge problem in day-to-day lives. Smartphone with internet, which actually revolutionized our lives is intruding every aspect of our life. According to the website, we are social; the 2018 statistical reported that the number of smartphone internet users is 4.021 billion. A mobile device with internet not only connects us with the whole world but also makes our lives easy by social networking, online shopping and other various things. To this point, it was fine but it started intruding in our lives and now we are facing many challenges because of such invasion. For example, relationships get affected by the amount of time spent with technology and cause conflict among partners. For instance, the time spent by men on videogame playing can increase the relationship conflicts and even spill over into relational aggression (Coyne et al., 2012).

We all use smartphones for different purposes and it made our day-to-day work easier but when this smartphone is being overused, it starts creating problems. Just imagine we are in some social gathering or while interacting to someone and he or she is holding her phone in hand and continuously watching or doing something with it while you are talking then, how will you feel? Recently this behavior caught the attention of various psychologists and all across the globe spread like wildfire among researchers. The specific term "Phubbing" was coined for this behavior which actually came from merging of two words, "phone" and "snubbing". It is the act of snubbing someone in a social setting by paying attention to one's phone instead of talking to the person directly in one's company (Haigh, 2012). Macquarie Dictionary originally coined this term for the campaign of representing the immense growing problem of smartphone misuse in social situations (Pathak, 2013). Phubbing usually occurs when people snub or ignore another person by concentrating on their smartphone (e.g., Abeele et al., 2016, Abramova et al., 2017, Nazir \& Pişkin, 2016, Ugur \& Koc, 2015). During a social interaction, a "Phubber" can be defined as a person who starts looking or using his smartphone and a "Phubbee" can be defined as a person who is a recipient of Phubbing behavior.

One recent study reported that during social activity, $90 \%$ of respondents used their smartphones, and perceived during the social interactions $86 \%$ others did the same (Ranie \& Zickuhr, 2015). In another similar study conducted in Ankara, Turkey, an attitude and emotional response among university students towards Phubbing was surveyed, and $86.7 \%$ male and $82.8 \%$ female students consider Phubbing as a growing issue (Nazir, 2017). So most researchers are trying to assess the impact of Phubbing in our social interactions, social gatherings and meetings and how it can influence our day-to-day social life.

Phubbing behavior makes face-to-face interaction less meaningful was reported by many researches. During a simulated conversation people who imagined they were being phubbed felt even more negatively than the people who 
didn't picture Phubbing was reported in one of the recent study (Chotpitayasunondh \& Douglas, 2018). Texting during face to face conversations made the talk less satisfying for the people having it and was found in another study published in Computers in Human Behavior in 2016, compared to people who interacted without phones (Drago, 2016). During conversations a mere presence of smartphone was enough to make people feel less connected to each other was found in a study (Ictech, 2014).

There are numerous studies, which are providing evidences of effects of Phubbing on social interactions as well as on our daily lives. The aim of this article is to understand the previous researches, which had been done in the area of smartphone addiction and try to understand the similarities and differences in both the phenomenon. This article tries to dig out the available literature to find out what actually Phubbing is and what can be its true determinants. In addition, it tried to understand various types of addictions, which can elevate the Phubbing behavior in different settings.

\section{Literature Review}

As the concept of Phubbing is not that old, the available researches and literature are limited and is not being categorized yet and we are trying to ascertain every titbit together in order to find what can be the actual determinants of Phubbing. Therefore, the literature can be divided according to the researches done and according to their headings, which are as below:

1) Smartphone addiction or Internet Addiction

2) Social Media Addiction

3) Gaming addiction

4) Personal and Situational factors

\subsection{Smart Phone Addiction or Internet Addiction}

"Nomophobia" i.e. the fear of being without a smartphone is a phone addiction which is often sparked by an Internet overuse problem or Internet addiction disorder. In DSM-V, addiction criteria addictive behavior has been defined as a psychological problem related to the use of technology unmelodious. Nowadays smartphones are loaded with so many features which go beyond even then the early computers and these features had huge effect on addiction. Such an excess use of these computers had compelled the researchers to understand and investigate the concept of computer addiction (Griffiths, 2000; Shaffer, 2002; Shotton, 1991). Most of these researchers found that it's not only computer which had impact of the addiction but those software's had huge impact on addiction. These are many examples of such software applications which compel a person to stay online for longer time such as Playing games online, shopping and social apps (Charlton \& Danforth, 2007; Weinstein \& Lejoyeux, 2010; Wood, 2008; Chou \& Hsiao, 2000; Lin \& Tsai, 2002; Yang \& Tung, 2007).

During the last decade the frequency and duration of internet have increased 
widely (Dong, Lu, Zhou, \& Zhao, 2011; Smahel, Brown, \& Blinka, 2012) and the increased duration of computer usage enslaves people has gained importance. Researches regarding internet and addiction and its seriousness begins first time during 1996 and excessive usage of internet usage can be found in DSM-IV classification with pathological gambling (1995) and time duration spend on the internet triggers pathological Internet use (Nalwa \& Anand, 2003). With the time this type of addiction became important and concerning topic for researchers (Ceyhan, 2008; Ghamari, Mohammadbeigi, Mohammadsalehi, \& Hashiani 2011). Most of the studies can be divided into two types according to their understanding of internet addiction. First some researchers believe that this type of addiction is a new kind of disorder and the second group of researchers on another hand tried to understand the internet usage contents such as online gaming, social media or pornography which is connected to the excess use of internet (Yellowlees \& Marks, 2007). On the basis of various researches it can be concluded that the reason for excessive usage of internet is due to the desire of many things such as pornography (Frangos, Frangos, \& Kiohos, 2010; Griffiths, 2012; Pallanti, Bernardi, \& Quercioli, 2006), Online gaming (Ceyhan, 2010; Gilbert, Murphy, \& McNally, 2011; Öztürk \& Özmen, 2011), and social media such a Facebook and Instagram (Akçay, 2011; Balc1 \& Gülnar, 2009; Ceyhan, 2011). At last we can conclude that the excess use of internet and the excessive time spent on internet and the desire of surfing vast and diverse contents may create problematic addiction but among the researchers there is no consensus for naming the existing problems.

This kind of addiction compels individual person to stay online and overuse internet for longer times and forgetting their real life and people around them and such behaviors in public or in social settings clearly illustrates the functioning of Phubbing.

\subsection{Social Media Addiction}

Social media initially was developed to ease out our mode of communication but it became an addiction (Karaiskos, Tzavellas, Balta, \& Paparrigopoulos, 2010; Turel \& Serenko, 2012). This mode of communication for example Facebook, Snapchat, WhatsApp, Tweeter, Instagram and even now there are many online playing game apps where a person can play games as well as chat with people simultaneously encouraged the person to remain online for longer times. All these modes of communication web applications and sites are becoming a fashion, acceptable and integral part of our daily lives and can be accessed easily from anywhere and anytime throw our smartphones. Due to these applications the utilization rate has drastically increased, and the use of these applications usage also plays an important role (Falaki et al., 2010). Among the addiction behavior, social media is having a significant place, which plays an important role in smartphone addiction also (Kwon et al., 2013). Social media can be one of the addiction objects within the smartphone addiction but without social media 
smartphone addiction can still survive even the smartphone don't have these applications. Among the social media Facebook and Twitter tops the list of sharing sites and their habitual usage turns to addiction (Andreassen, Torsheim, Brunborg, \& Pallesen, 2012; Malita, 2011). These social media which are perfect blend of entertainment as well as interactive social sharing places which people nowadays love to share their feelings, thoughts, memories etc. For example the initial purpose of Facebook was to interact with friends who can't be reached easily due to distance but now its use and purpose had turned another way and researchers found that the most common reason among $69.57 \%$ people to use Facebook is to serf other profiles and $58.70 \%$ looks to see their photos (Pempek, Yermolayeva, \& Calvert, 2009). Twitter had also become the object of addiction as it let individual use it as social networking service on which a person posts and interact with messages with multiple people simultaneously and follow their friends and famous people all around the world (Malita, 2011). In nutshell, these social network websites became important and devastating concerns, which enhance the behavior of addiction, and these websites continuously reinforce the behavior of addiction to the smartphones. These social networking sites let individual person to live in a virtual world and trying to show their presence in that virtual world and forgetting their real life and people around them and such behaviors in public or in social settings clearly illustrates the functioning of Phubbing.

\subsection{Gaming Addiction}

Computer gaming or with the modern technologically advance smartphones which are loaded with games became the source of addiction and these games turns as a source of phone addiction. Studies had found that those people who lack management of time and in order to escape from the real-life problems use gaming as a mental relaxation tool (Wood, 2008).

Game addiction refers to online games, video games and computer games. All of these types of gaming have substantially the same origin and they all refers to playing computer games to the extent when it starts effecting day to day life and is regarded as addictive behavior (Weinstein \& Lejoyeux, 2010; Charlton \& Danforth, 2010; Kim, Namkoong, Ku, \& Kim, 2008; Lo, Wang, \& Fang, 2005; Young, 2009; Chiu, Lee, \& Huang, 2004; Kim, Namkoong, Ku, \& Kim, 2008; Grüsser, Thalemann, \& Griffiths, 2006). Gaming plays and important role in phubbing as it leads person to smartphone addiction as individual want to stay online for longer times and forget his real world and social surroundings. All these addictions and very hard to separate from each other as they have mutual relationship and are intertwined between each other. Modern social networking companies use a lot of techniques to attract the audience and they use gaming as one of the techniques to keep users busy and online for longer durations. For example, Facebook had introduced online game Candy Crush and Angry Birds (Walsh, White, \& Young, 2008; Böhmer, Hecht, Schöning, Krüger, \& Bauer, 2011). They are the most widely played games on cyber world in social media websites 
and they attract people and keep them busy and online for longer times and people are becoming almost addictive. This type of behavior shown in public can lead to Phubbing and people may forget the people sitting around them. Therefore, this kind of gaming addiction may enhance the Phubbing phenomenon in social settings and can be one of the determinant of the Phubbing behavior.

\subsection{Personal and Situational Factors}

Phubbing a new phenomenon that is not been studied so deeply, in depth and having the limitations regarding the prevailing researches. Therefore, here is a hypothesis of the factors, which may be personal or situational, and plays and important role in understanding this phenomenon. Personal factors may include introversion, deliberate ignoring, Tiredness, not interesting in talking to someone who is sitting beside and, on another side, the situational factors can be diverse such as a person is expecting some important or serious news so that keep him checking smartphone often or his favorites team is playing and he continuously is checking the score etc. Sometimes in a long lecture or in a meeting people had been often seen Phubbing instead of listening but here too due to boredom they need a break so they often take smartphone out in order to surf and it's a kind of mental break they are taking. In addition, smartphones are multifunctional and there uses in social settings can vary from using it as a watch to time management by simply installing an app in it. Therefore, it is a debatable issue under which situation a person is Phubber. In many social setting now people start accepting it as normal but while face to face communication people feel frustrating and people get annoyed and $83.3 \%$ people in a survey responded that they get annoyed if they face Phubbing (Nazir, 2017).

\section{Discussion}

Different researches and the literature regarding what claims to be the determinants of Phubbing such as Smartphone addiction or Internet Addiction, Social Media Addiction and Gaming addiction had been examined in brief. In the above literature, researcher also tried to understand what all these addictions actually mean and how they influence human behavior while either alone or in social settings. Here let us explain and try to understand Phubbing phenomenon once again and what are the key and necessary conditions and components and then it can be related to the above-mentioned addictions. After all this it can be understood that what can be the actually determinants and what can be the other variables which enhance Phubbing behavior.

As early-defined Phubbing is the act of snubbing someone in a social setting by paying attention to one's phone instead of talking to the person directly in one's company. This definition is having very important component, which is Phubbing, is a snubbing in social setting. This means that the presence of another person is important and if the second person is not present then it is not Phubbing. Maybe a person can be addicted as mentioned above in litera- 
ture but it cannot be considered as Phubbing because the person needs to do the same in social settings. In today's modern life where people are, too much addicted to their smartphones and even around us in streets people using their smartphones while walking, waiting for bus or metro and again same cannot be considered as Phubbing if another person who is being effected does not accompany them.

Phubbing can happen anywhere while people are sitting with a company of their friend or friends, while sitting in the meetings, eating or sitting with their family, social gatherings or even if a person is walking with someone or waiting for a metro or bus at station with his friends or family member. It is influencing our relationships; our business and it is influencing us as a whole. It had changed the way we used to have face-to-face conversations and it had completely influenced our social interaction structure. In a recent study conducted in Ankara, Turkey around $86.2 \%$ of students thought that the person they are talking to doesn't listen to them because of Phubbing and $83.3 \%$ of people get annoyed (Nazir, 2017).

Now discussing the above-mentioned different addictions which can determine the frequency of Phubbing behavior are important but such behaviors when are done by a person alone cannot be considered as Phubbing and can be evaluated as addictions. Yes, these addictions can spark the frequency of Phubbing behavior and these can definitely determine the frequency of Phubbing behavior but cannot be always correlated with Phubbing phenomenon. A person might be addicted but he cannot be considered as phubber as many addicted to smartphone might not use their smartphones during social settings. Thus, it can be assumed that not every Phubber might be having above-mentioned addiction.

\section{Conclusion}

In today's modern world, life is transforming very fast, so the smartphone is the mean and mode of communications. Phubbing has evolved with time and is becoming a serious concern. The Phubbing phenomenon must be studied through the broader lens as Society and Culture play a very important role in such behavior. People may feel bored during meetings, seminars or even in class, lectures and they start Phubbing. During the lectures, we see students using the smartphones and professors may accept it unless and until they are not disturbing class, and it is becoming a social norm. But on another side, it is affecting us by one way or another way and it is affecting our relationships and our feelings as a study found that $63.1 \%$ people during an informal meet with friends felt that they are not important for a person who is sitting with them and is Phubbing (Nazir, 2017).

\section{Conflicts of Interest}

The authors declare no conflicts of interest regarding the publication of this paper. 


\section{References}

Abeele, M. M. P. V. et al. (2016). The Effect of Mobile Messaging during a Conversation on Impression Formation and Interaction Quality Computers. Human Behavior, 62, 562-569. https://doi.org/10.1016/j.chb.2016.04.005

Abramova, O., Baumann, A., Krasnova, H., \& Lessmann, S. (2017). To Phub or Not to Phub: Understanding Off-Task Smartphone Usage and Its Consequences in the Academic Environment (No. 87717). Darmstadt: Darmstadt Technical University, Department of Business Administration, Economics and Law, Institute for Business Studies (BWL).

Akçay, H. (2011). Social Media Use with the Context of Uses and Gratification: A Research on Gumushane University. Journal of Communication Theory and Research, $33,138-161$.

Andreassen, C. S., Torsheim, T., Brunborg, G. S., \& Pallesen, S. (2012). Development of a Facebook Addiction Scale 1, 2. Psychological Reports, 110, 501-517.

https://doi.org/10.2466/02.09.18.PR0.110.2.501-517

Balc1, Ş., \& Gülnar, B. (2009). Internet Addiction among University Students and the Profile of Internet Addicts. Journal of Selcuk Communication, 6, 5-22.

Böhmer, M., Hecht, B., Schöning, J., Krüger, A., \& Bauer, G. (2011). Falling Asleep with Angry Birds, Facebook and Kindle: A Large Scale Study on Mobile Application Usage. In Proceedings of the 13th International Conference on Human Computer Interaction with Mobile Devices and Services (pp. 47-56). New York: ACM. https://doi.org/10.1145/2037373.2037383

Ceyhan, A. A. (2011). University Students' Problematic Internet Use and Communication Skills According to Internet Use Purposes. Educational Science: Theory \& Practice, 11, 59-77.

Ceyhan, E. (2008). A Risk Factor for Adolescent Mental Health: Internet Addiction. Turkish Journal of Child and Adolescent Mental Health, 15, 109-116.

Ceyhan, E. (2010). Predictiveness of Identity Status, Main Internet Use Purposes and Gender on University Students' Problematic Internet Use. Educational Sciences: Theory \& Practice, 10, 1323-1355.

Charlton, J. P., \& Danforth, I. D. (2007). Distinguishing Addiction and High Engagement in the Context of Online Game Playing. Computers in Human Behavior, 23, 1531-1548. https://doi.org/10.1016/j.chb.2005.07.002

Charlton, J. P., \& Danforth, I. D. W. (2010). Validating the Distinction between Computer Addiction and Engagement: Online Game Playing and Personality. Behaviour \& Information Technology, 29, 601-613. https://doi.org/10.1080/01449290903401978

Chiu, S. I., Lee, J. Z., \& Huang, D. H. (2004). Video Game Addiction in Children and Teenagers in Taiwan. Cyber Psychology \& Behavior, 7, 571-581. https://doi.org/10.1089/cpb.2004.7.571

Chotpitayasunondh, \& Douglas (2018). The Effects of "Phubbing" on Social İnteraction. Jouranl of Applied Social Psychology, 48, 304-316. https://doi.org/10.1111/jasp.12506

Chou, C., \& Hsiao, M. C. (2000). Internet Addiction, Usage, Gratification, and Pleasure Experience: The Taiwan College Students' Case. Computers \& Education, 35, 65-80. https://doi.org/10.1016/S0360-1315(00)00019-1

Coyne, S. M., Busby, D., Bushman, B. J., Gentile, D. A., Ridge, R., \& Stockdale, L. (2012). Gaming in the Game of Love: Effects of Video Games on Conflict in Couples. Family Relations, 61, 388-396. https://doi.org/10.1111/j.1741-3729.2012.00712.x

Dong, G., Lu, Q., Zhou, H., \& Zhao, X. (2011). Precursor or Sequela: Pathological Dis- 
orders in People with Internet Addiction Disorder. PLoS ONE, 6, e14703. https://doi.org/10.1371/journal.pone.0014703

Drago, E. (2016). The Effect of Technology on Face-to-Face Communication. The Elon Journal of Undergraduate Research in Communications, 6, 13-19.

Falaki, H., Mahajan, R., Kandula, S., Lymberopoulos, D., Govindan, R., \& Estrin, D. (2010). Diversity in Smartphone Usage. In Proceedings of the 8th International Conference on Mobile Systems, Applications, and Services (pp. 179-194). New York: ACM. https://doi.org/10.1145/1814433.1814453

Frangos, C., Frangos, C., \& Kiohos, A. (2010). Internet Addiction among Greek University Students: Demographic Associations with the Phenomenon, Using the Greek Version of Young's Internet Addiction. International Journal of Economic Sciences and Applied Research, 1, 49-74.

Ghamari, F., Mohammadbeigi, A., Mohammadsalehi, N., \& Hashiani, A. A. (2011). Internet Addiction and Modeling Its Risk Factors in Medical Students, Iran. Indian Journal of Psychological Medicine, 33, 158. https://doi.org/10.4103/0253-7176.92068

Gilbert, R. L., Murphy, N. A., \& McNally, T. (2011). Addiction to the 3-Dimensional Internet: Estimated Prevalence and Relationship to Real World Addictions. Addiction Research \& Theory, 19, 380-390. https://doi.org/10.3109/16066359.2010.530714

Griffiths, M. (2000). Does Internet and Computer "Addiction" Exist? Some Case Study Evidence. Cyber Psychology and Behavior, 3, 211-218. https://doi.org/10.1089/109493100316067

Griffiths, M. D. (2012). Internet Sex Addiction: A Review of Empirical Research. Addiction Research \& Theory, 20, 111-124. https://doi.org/10.3109/16066359.2011.588351

Grüsser, S. M., Thalemann, R., \& Griffiths, M. D. (2006). Excessive Computer Game Playing: Evidence for Addiction and Aggression? CyberPsychology \& Behavior, 10, 290-292. https://doi.org/10.1089/cpb.2006.9956

Haigh, A. (2012). Stop Phubbing. http://www.stopphubbing.com

Ictech, B. (2014). Smartphones and Face-to-Face Interactions: Extending Goffman to 21st Century Conversation. Theses and Dissertations, New Orleans, LA: University of New Orleans.

Karaiskos, D., Tzavellas, E., Balta, G., \& Paparrigopoulos, T. (2010). P02-232-Social Network Addiction: A New Clinical Disorder? European Psychiatry, 25, 855. https://doi.org/10.1016/S0924-9338(10)70846-4

Kim, E. J., Namkoong, K., Ku, T., \& Kim, S. J. (2008). The Relationship between Online Game Addiction and Aggression, Self-Control and Narcissistic Personality Traits. European Psychiatry, 23, 212-218. https://doi.org/10.1016/j.eurpsy.2007.10.010

Kwon, M., Lee, J. Y., Won, W. Y., Park, J. W., Min, J. A., Hahn, C., Gu, X., Choi, J. H., \& Kim, D. J. (2013). Development and Validation of a Smartphone Addiction Scale (SAS). PLoS ONE, 8, e56936. https://doi.org/10.1371/journal.pone.0056936

Lin, S. S., \& Tsai, C. C. (2002). Sensation Seeking and Internet Dependence of Taiwanese High School Adolescents. Computers in Human Behavior, 18, 411-426. https://doi.org/10.1016/S0747-5632(01)00056-5

Lo, S. K., Wang, C. C., \& Fang, W. (2005). Physical Interpersonal Relationships and Social Anxiety among Online Game Players. Cyber Psychology \& Behavior, 8, 15-20. https://doi.org/10.1089/cpb.2005.8.15

Malita, L. (2011). Social Media Time Management Tools and Tips. Procedia Computer Science, 3, 747-753. https://doi.org/10.1016/j.procs.2010.12.123

Nalwa, K., \& Anand, A. P. (2003). Internet Addiction in Students: A Cause of Concern. 
Cyber Psychology \& Behavior, 6, 653-656.

https://doi.org/10.1089/109493103322725441

Nazir, T. (2017). Attitude and Emotional Response among University Students of Ankara towards Phubbing. International Journal of Multidisciplinary Educational Research, 6, 11.

Nazir, T., \& Pişkin, M. (2016). Phubbing: A Technological Invasion Which Connected the World But Disconnected Humans. International Journal of Indian Psychology, 3, 39-46.

Öztürk, E., \& Özmen, S. K. (2011). An Investigation of the Problematic Internet Use of Teacher Candidates Based on Personality Types, Shyness and Demographic Factors. Educational Sciences: Theory \& Practice, 11, 1785-1808.

Pallanti, S., Bernardi, S., \& Quercioli, L. (2006). The Shorter PROMIS Questionnaire and the Internet Addiction Scale in the Assessment of Multiple Addictions in a High-School Population: Prevalence and Related Disability. CNS Spectrums, 11, 966-974. https://doi.org/10.1017/S1092852900015157

Pathak, S. (2013). McCann Melbourne Made up a Word to Sell a Print Dictionary: New Campaign for Macquarie Birthed "Phubbing".

http://adage.com/article/news/mccann-melbourne-made-aword-sell-a-dictionary/2445 $\underline{95}$

Pempek, T. A., Yermolayeva, Y. A., \& Calvert, S. L. (2009). College Students' Social Networking Experiences on Facebook. Journal of Applied Developmental Psychology, 30, 227-238. https://doi.org/10.1016/j.appdev.2008.12.010

Ranie, L., \& Zickuhr, K. (2015). Americans' Views on Mobile Etiquette. Washington DC: Pew Research Center.

http://www.pewinternet.org/2015/08/26/americans-views-on-mobile-etiquette

Shaffer, H. J. (2002). Is Computer Addiction a Unique Psychiatric Disorder. Psychiatric Times, 19, 2.

Shotton, M. A. (1991). The Costs and Benefits of "Computer Addiction". Behaviour \& Information Technology, 10, 219-230. https://doi.org/10.1080/01449299108924284

Smahel, D., Brown, B. B., \& Blinka, L. (2012). Associations between Online Friendship and Internet Addiction among Adolescents and Emerging Adults. Developmental Psychology, 48, 381. https://doi.org/10.1037/a0027025

Turel, O., \& Serenko, A. (2012). The Benefits and Dangers of Enjoyment with Social Networking Websites. European Journal of Information Systems, 21, 512-528. https://doi.org/10.1057/ejis.2012.1

Ugur, N. G., \& Koc, T. (2015). Time for Digital Detox: Misuse of Mobile Technology and Phubbing. Procedia-Social and Behavioral Sciences, 195, 1022-1031. https://doi.org/10.1016/j.sbspro.2015.06.491

Walsh, S. P., White, K. M., \& Young, R. M. (2008). Over-Connected? A Qualitative Exploration of the Relationship between Australian Youth and Their Mobile Phones. Journal of Adolescence, 31, 77-92. https://doi.org/10.1016/j.adolescence.2007.04.004

Weinstein, A., \& Lejoyeux, M. (2010). Internet Addiction or Excessive Internet Use. The American Journal of Drug and Alcohol Abuse, 36, 277-283. https://doi.org/10.3109/00952990.2010.491880

Wood, R. T. (2008). Problems with the Concept of Video Game "Addiction": Some Case Study Examples. International Journal of Mental Health and Addiction, 6, 169-178. https://doi.org/10.1007/s11469-007-9118-0

Yang, S. C., \& Tung, C. J. (2007). Comparison of Internet Addicts and Non-Addicts in 
Taiwanese High School. Computers in Human Behavior, 23, 79-96.

https://doi.org/10.1016/j.chb.2004.03.037

Yellowlees, P. M., \& Marks, S. (2007). Problematic Internet Use or Internet Addiction? Computers in Human Behavior, 23, 1447-1453.

https://doi.org/10.1016/j.chb.2005.05.004 